\title{
In vitro susceptibility of six isolates of equine herpesvirus 1 to acyclovir, ganciclovir, cidofovir, adefovir, PMEDAP and foscarnet
}

\author{
B. Garré ${ }^{\mathrm{a}, \mathrm{b}, *}$, K. van der Meulen ${ }^{\mathrm{a}}$, J. Nugent ${ }^{\mathrm{c}}, \mathrm{J}_{\text {. Neyts }}{ }^{\mathrm{d}}$, S. Croubels ${ }^{\mathrm{b}}$, \\ P. De Backer ${ }^{b}$, H. Nauwynck ${ }^{a}$ \\ ${ }^{a}$ Laboratory of Virology, Faculty of Veterinary Medicine, Ghent University, Salisburylaan 133, 9820 Merelbeke, Belgium \\ ${ }^{\mathrm{b}}$ Department of Pharmacology, Toxicology, Biochemistry and Organ Physiology, Faculty of Veterinary Medicine, \\ Ghent University, Salisburylaan 133, 9820 Merelbeke, Belgium \\ ${ }^{\mathrm{c}}$ Animal Health Trust, Kentford, Newmarket, United Kingdom \\ ${ }^{\mathrm{d}}$ Rega Institute for Medical Research, University of Leuven, Minderbroedersstraat 10, 3000 Leuven, Belgium
}

Received 2 October 2006; received in revised form 21 December 2006; accepted 3 January 2007

\begin{abstract}
Equine herpesvirus 1 (EHV-1) is an important equine pathogen that causes respiratory disease, abortion, neonatal death and paralysis. Although vaccines are available, they are not fully protective and outbreaks of disease may occur in vaccinated herds. Therefore, there is an urgent need for effective antiviral treatment. For three abortigenic (94P247, 97P70 and 99P96) and three neuropathogenic isolates (97P82, 99P136 and 03P37), the effect of acyclovir, ganciclovir, cidofovir, adefovir, 9-(2-phosphonylmethoxyethyl)-2,6-diaminopurine (PMEDAP) and foscarnet on plaque number was studied. Additionally, for isolate 97P70, the effect on plaque size was investigated. Ganciclovir was most potent in reducing plaque number, followed by PMEDAP and acyclovir. Adefovir and cidofovir were less effective and foscarnet was the least effective compound. There were no differences detected for acyclovir, ganciclovir, adefovir and PMEDAP between the abortigenic and neuropathogenic isolates. One abortigenic isolate (99P96) was more susceptible to cidofovir and two neuropathogenic isolates (99P136 and 03P37) were less susceptible to foscarnet. For isolate 97P70, all compounds resulted in a significant reduction of plaque size. The most remarkable effect was observed for cidofovir. It was 40 -fold more effective in reducing plaque size than in reducing plaque number. In conclusion, ganciclovir was the most potent compound and therefore, may be a valuable candidate for the treatment of EHV-1 infections in horses. The antiviral effect of foscarnet on plaque number was highly dependent on the viral isolate tested. Therefore, it is no valuable antiviral for the treatment of herpesvirus-infections. Cidofovir, although less effective in reducing plaque number, had a strong effect on plaque size.
\end{abstract}

(C) 2007 Elsevier B.V. All rights reserved.

Keywords: EHV-1; Antivirals; In vitro; Isolates

* Corresponding author at: Department of Pharmacology, Toxicology, Biochemistry and Organ Physiology, Faculty of Veterinary Medicine, Salisburylaan 133, Ghent University, 9820 Merelbeke, Belgium. Tel.: +32 9264 73 46; fax: +32 92647497.

E-mail address: barbara.garre@ugent.be (B. Garré). 


\section{Introduction}

Equine herpesvirus 1 (EHV-1), a member of the Alphaherpesvirinae, is a major pathogen of horses. The virus is endemic worldwide and most horses become infected during their first year of life (Ostlund, 1993). After exposure, EHV-1 replicates in the upper respiratory tract. This can be associated with respiratory disorders, characterised by fever, anorexia, nasal discharge of varying severity and ocular discharge (Patel and Heldens, 2005), or the infection can be silent (Foote et al., 2006). Replication is followed by a leukocyte-associated viremia which enables EHV-1 to reach internal organs. There, its replication can result in abortion, neonatal death or nervous system disorders (Allen and Bryans, 1986; Bryans and Allen, 1989). Abortion can involve only one or two mares in a herd but also abortion storms can occur on a premise, associated with great economic losses (Allen and Bryans, 1986). Neurological disorders have been reported with increasing frequency (McMartan et al., 1995; Friday et al., 2000; van Maanen et al., 2001; Stierstorfer et al., 2002; van der Meulen et al., 2003a) and during an outbreak many cases may occur with devastating effects.

Although vaccines against EHV-1 are available, they are not fully protective (Kydd et al., 2006; Goodman et al., 2006; van der Meulen et al., 2006a) and outbreaks of disease may still occur (Buchner and Mostl, 1998; Friday et al., 2000; van der Meulen et al., 2000; Kohn et al., 2003; Goehring et al., 2006). Therefore, there is a need for effective antiviral chemotherapy. Antivirals need to meet several requirements. They have to reduce viral replication and spread in affected horses, and prevent viral replication in in-contact animals. The drug should be effective against isolates of EHV-1 associated with outbreaks of abortion as well as those associated with outbreaks of neurological disorders. Recently, it was postulated that a variation of a single amino acid of the DNA polymerase is strongly associated with neurological versus non-neurological disease outbreaks (Nugent et al., 2006). This may have an implication on the susceptibility of various isolates to anti-herpetic compounds as many of these compounds act on the DNA polymerase (De Clercq, 2004). Finally, the drug should be safe and devoid of adverse effects.

Some antivirals have already been tested in vitro for their efficacy to inhibit EHV-1 replication by means of a plaque reduction assay, i.e. ganciclovir (Smith et al., 1983; Rollinson and White, 1983; Rollinson, 1987), three 2'-fluoropyrimidine nucleosides (Rollinson, 1987), (S)-9-[3-hydroxy-2-phosphonylmethoxypropyl]adenine or HPMPA (Field and Awan, 1990) and the HPMPA analogue cidofovir (Gibson et al., 1992). These compounds proved more effective than 9[4-hydroxy-3-hydroxymethylbut-1-yl]guanine (Boyd et al., 1987) and penciclovir (de la Fuente et al., 1992). For acyclovir, contradictory data have been reported. Rollinson and White (1983) reported a 6-fold lower EC $_{50}$ than Boyd et al. (1987). Further, based on comparison of $\mathrm{EC}_{50}$-values reported in literature, adefovir would be the least active compound in this series (Field and Awan, 1990). However, data of these different studies are difficult to compare as different isolates, cell lines and assays have been employed.

The aim of the present study was to compare the efficacy of acyclovir, ganciclovir, cidofovir, adefovir, PMEDAP and foscarnet against EHV-1 in vitro. Four of these products have already been tested in vitro while foscarnet and PMEDAP are new in this study. Three abortigenic and three neuropathogenic isolates of EHV-1 were included and one cell line, EEL cells, was used. Additionally, the efficacy of the antivirals to reduce the size of EHV-1 induced plaques was investigated. Reduction in plaque size may be a potential parameter for the ability of an antiviral to inhibit cell to cell spread and, consequently to restrict the size of macroscopic lesions in vivo.

\section{Materials and methods}

\subsection{Cells}

All studies were conducted using equine embryonic lung (EEL) cells. EEL cells were cultured in growth medium (minimum essential medium (MEM) supplemented with $100 \mathrm{U} / \mathrm{ml}$ penicillin, $0.1 \mathrm{mg} / \mathrm{ml}$ streptomycin, $0.1 \mathrm{mg} / \mathrm{ml}$ kanamycin, $0.3 \mathrm{mg} / \mathrm{ml}$ glutamine and 5\% foetal calf serum). Cells were passaged once a week.

\subsection{Viruses}

Six Belgian EHV-1 isolates were tested. The isolates 94P247, 97P70 and 99P96 were isolated 
Table 1

Characteristics of the EHV-1 isolates

\begin{tabular}{|c|c|c|c|c|}
\hline Viral isolate & Isolated from & ORF30 $752^{\mathrm{a}}(\mathrm{D} / \mathrm{N})$ & ORF68 strain $^{\mathrm{b}}$ grouping & Origin \\
\hline 94P247 & Abortion & $\mathrm{N}$ & 3 & Kluisbergen $\left(50^{\circ} 46^{\prime}\right.$ north $-03^{\circ} 29^{\prime}$ east $)$ \\
\hline 97P70 & Abortion & $\mathrm{N}$ & 3 & Gouy-les-Pieton $\left(50^{\circ} 25^{\prime}\right.$ north- $04^{\circ} 25^{\prime}$ east $)$ \\
\hline 99P96 & Abortion & $\mathrm{N}$ & 3 & Hamme $\left(51^{\circ} 05^{\prime}\right.$ north $-04^{\circ} 08^{\prime}$ east $)$ \\
\hline 97P82 & Neurological disorders & $\mathrm{D}$ & 2 & Nijvel $\left(50^{\circ} 35^{\prime}\right.$ north $-04^{\circ} 19^{\prime}$ east $)$ \\
\hline 99P136 & Neurological disorders & $\mathrm{D}$ & 3 & Kampenhout $\left(50^{\circ} 57^{\prime}\right.$ north $-04^{\circ} 34^{\prime}$ east $)$ \\
\hline 03P37 & Neurological disorders & $\mathrm{D}$ & 3 & Kozen $\left(50^{\circ} 55^{\prime}\right.$ north $-05^{\circ} 20^{\prime}$ east $)$ \\
\hline
\end{tabular}

${ }^{\text {a }}$ Nugent et al. (2006): ORF30 sequence variation is associated with pathogenic potential: $95 \%$ of the non-neurological isolates encoded $\mathrm{A}_{2254}$ (amino acid $\mathrm{N}_{752}$ ), $86 \%$ of the neurological isolates encoded $\mathrm{G}_{2254}$ (amino acid $\mathrm{D}_{752}$ ).

b Nugent et al. (2006): ORF68 as the primary strain grouping marker (geographical restriction of certain strain groups).

from lungs of an aborted fetus in 1994, 1997 and 1999, respectively. The isolates 97P82, 99P136 and 03P37 were isolated from the peripheral blood mononuclear cells (PBMC) of paralytic horses in 1997, 1999 and 2003 , respectively. They have been sequenced across the ORF30 region associated with differences between neurological versus non-neurological isolates (Nugent et al., 2006). The abortigenic isolates were typed $N_{752}$ and the neuropathogenic isolates were typed $\mathrm{D}_{752}$ (Table 1). They have also been sequenced across the ORF68 region. The ORF68 region is used as a marker system for distinguishing isolates into 6 common strain groups (Nugent et al., 2006). Five of the six isolates were located in strain group 3, while only the isolate 97P82 was located in strain group 2 (Table 1). Virus used for the experiments was between the fourth and sixth passage.

\subsection{Antiviral compounds}

The antiviral compounds used were acyclovir (GlaxoSmithKline, Genval, Belgium), ganciclovir (Roche Bioscience, Palo Alto, CA, USA), cidofovir and adefovir (Gilead Sciences, Foster City, CA, USA), 9-(2-phosphonylmethoxyethyl)-2,6-diaminopurine (PMEDAP) and foscarnet (Astra Zeneca, Södertälje, Sweden). Compounds were dissolved in Roswell Park Memorial Institute (RPMI)-1640 medium at a concentration of $1 \mathrm{mg} / \mathrm{ml}$ and stored at $4{ }^{\circ} \mathrm{C}$ until use.

\subsection{Antiviral assays}

EEL-cells were seeded in 24-well culture plates (Nunc A/S) at a density of 300,000 cells/well and were cultured at $37{ }^{\circ} \mathrm{C}$ for $24 \mathrm{~h}$. Then, growth medium was removed and cultures were infected with $40 \mathrm{PFU}$ of
EHV-1/well. After $1 \mathrm{~h}$, virus was removed. Cells were rinsed twice with culture medium and overlaid with carboxymethylcellulose $0.94 \%$ overlay medium (Sigma) containing serial dilutions of each compound. Infected, untreated cells served as control. Overlay medium was removed at $50 \mathrm{~h}$ post inoculation and cells were rinsed with PBS, after which the cell monolayer was fixed with $4 \%$ paraformaldehyde and methanol $+1 \% \mathrm{H}_{2} \mathrm{O}_{2}$. Subsequently, an immunoperoxidase monolayer assay (IPMA) was performed. In brief, polyclonal antibodies against EHV-1 (van der Meulen et al., 2003b) were added for $1 \mathrm{~h}$ at $37^{\circ} \mathrm{C}$ and, after three washing steps, goat anti-horse antibodies labeled with peroxidase (Jackson, De Pinte, Belgium) were added for $1 \mathrm{~h}$ at $37^{\circ} \mathrm{C}$. Again, three washing steps were performed, before adding the substrate 3-amino-9-ethylcarbazole (AEC) (Sigma). After 6 min of incubation at $37^{\circ} \mathrm{C}$, substrate was replaced by acetate buffer to block enzymatic reaction.

The number of EHV-1 induced plaques was counted for each concentration of antiviral compound and for untreated control samples using light microscopy (Olympus IX50). The inhibitory effect of the antiviral compounds on plaque number was calculated by following formula:

$$
\begin{aligned}
& \text { Percentage inhibition } \\
& \quad=\left[1-\frac{\text { (number of plaques) antiviral }}{\text { (number of plaques) control }}\right] \times 100 \%
\end{aligned}
$$

The concentration of each compound required to reduce the plaque number by $50 \%\left(\mathrm{EC}_{50}\right)$ was hand-calculated from the dose-response curves generated from the data.

For isolate 97P70, the effect of the antiviral compounds on virus-induced plaque size was 
determined. Plaques were photographed using light microscopy (Olympus IX50) and a digital camera (Sony Progressive 3CCD), attached to a Macintosh computer. Plaques were randomly selected in each sample. At least three plaques were measured per well to allow statistical analysis. No more than 18 plaques were measured as this was the maximum number of well-isolated plaques per recipient (mean number measured per sample was $11.5 \pm 3.3$ ). Then, the size of the area of each plaque was determined in pixels using Scion 1.63 (National Institutes of Health, Bethesda, Maryland, USA) and finally, the mean plaque size was calculated for each concentration of antiviral.

For each experiment, three independent replicates were performed.

\subsection{Cytotoxicity assay}

The effect of the antiviral compounds on the viability of EEL cells was measured using an MTTbased method (Hansen et al., 1989). In brief, EELcells were seeded in 96-well culture plates (Nunc $\mathrm{A} / \mathrm{S}$ ) at a density of 50,000 cells/well. After $24 \mathrm{~h}$, growth medium was replaced by serial dilutions of the compounds. Untreated cells served as control. Cells fixed with $4 \%$ paraformaldehyde were included as background condition. At $69 \mathrm{~h}$ post incubation, cells were incubated with $0.3 \%$ MTT (Sigma, Bornem, Belgium) and were further incubated for $3 \mathrm{~h}$ at $37^{\circ} \mathrm{C}$ to allow the production of formazan. Then, MTT containing culture medium was removed and $150 \mu \mathrm{l}$ of detergent reagent $(0.5 \%$ sodium dodecyl sulphate in isopropanol) was added. Absor- bance was measured on a Multiskan RC (Thermo Labsystems, Brussel, Belgium) at a wavelength of $550 \mathrm{~nm}$. Viability of cells was calculated by following formula:

Percentage of viable cells $=\frac{\mathrm{ODt}-\mathrm{ODd}}{\mathrm{ODc}-\mathrm{ODd}} \times 100 \%$

where ODt is the absorbency of cells incubated with antiviral compounds, ODd the absorbency of the background control and ODc the absorbency of the untreated cells.

For each concentration of antiviral compound and for control samples, eight wells were tested per experiment. Three independent replicates of each experiment were performed.

\subsection{Data analysis}

Statistical analysis was based on analysis of variance (ANOVA) using SPSS (SPSS Inc., Chicago, IL, USA).

\section{Results}

\subsection{Effect of the antiviral compounds on plaque number}

The mean $\mathrm{EC}_{50}$-values \pm standard deviations are presented in Table 2. Ganciclovir proved most potent against all isolates and inhibited viral replication with a $50 \%$ effective concentration $\left(\mathrm{EC}_{50}\right)$ of $0.1-0.4 \mu \mathrm{g} /$ $\mathrm{ml}$. The efficacy of acyclovir $(1.7-3.0 \mu \mathrm{g} / \mathrm{ml})$ and the experimental molecule PMEDAP $(1.3-2.9 \mu \mathrm{g} / \mathrm{ml})$

Table 2

Susceptibility of 6 isolates of EHV-1 to antiviral compounds

\begin{tabular}{|c|c|c|c|c|c|c|}
\hline \multirow[t]{2}{*}{ Viral isolate } & \multicolumn{6}{|c|}{$\mathrm{EC}_{50} \pm$ S.D. $(\mathrm{ng} / \mathrm{ml})$} \\
\hline & Acyclovir & Ganciclovir & Cidofovir & Adefovir & PMEDAP & Foscarnet \\
\hline $94 \mathrm{P} 247$ & $2.7 \pm 0.5$ & $0.2 \pm 0.2$ & $5.8 \pm 2.7$ & $4.4 \pm 1.4$ & $1.5 \pm 0.1$ & $11.1 \pm 2.5$ \\
\hline $97 \mathrm{P} 70$ & $2.0 \pm 0.7$ & $0.2 \pm 0.1$ & $4.4 \pm 0.4$ & $4.3 \pm 0.7$ & $2.1 \pm 0.4$ & $6.9 \pm 0.8^{+}$ \\
\hline $99 \mathrm{P} 96$ & $1.7 \pm 0.5$ & $0.2 \pm 0.0$ & $1.1 \pm 0.6^{*}$ & $2.8 \pm 1.8$ & $1.3 \pm 1.0$ & $6.6 \pm 1.1^{+}$ \\
\hline 97P82 & $2.2 \pm 1.2$ & $0.1 \pm 0.1$ & $3.1 \pm 1.5$ & $4.2 \pm 2.0$ & $2.0 \pm 0.7$ & $7.9 \pm 2.6^{\#}$ \\
\hline 99P136 & $2.5 \pm 1.0$ & $0.3 \pm 0.1$ & $4.8 \pm 2.1$ & $5.6 \pm 1.2$ & $2.3 \pm 0.6$ & $16.2 \pm 2.6^{+, \#}$ \\
\hline 03P37 & $3.0 \pm 0.4$ & $0.4 \pm 0.1$ & $6.7 \pm 1.2^{*}$ & $3.8 \pm 1.8$ & $2.9 \pm 0.2$ & $15.8 \pm 3.6^{+}$ \\
\hline
\end{tabular}

* Significant difference between isolate $99 \mathrm{P} 96$ and isolate $03 \mathrm{P} 37$.

+ Significant difference between the isolates 97P70 and 99P96 on one hand, and the isolates 99P136 and 03P37 on the other hand.

\# Significant difference between isolate 97P82 and isolate 99P136. 

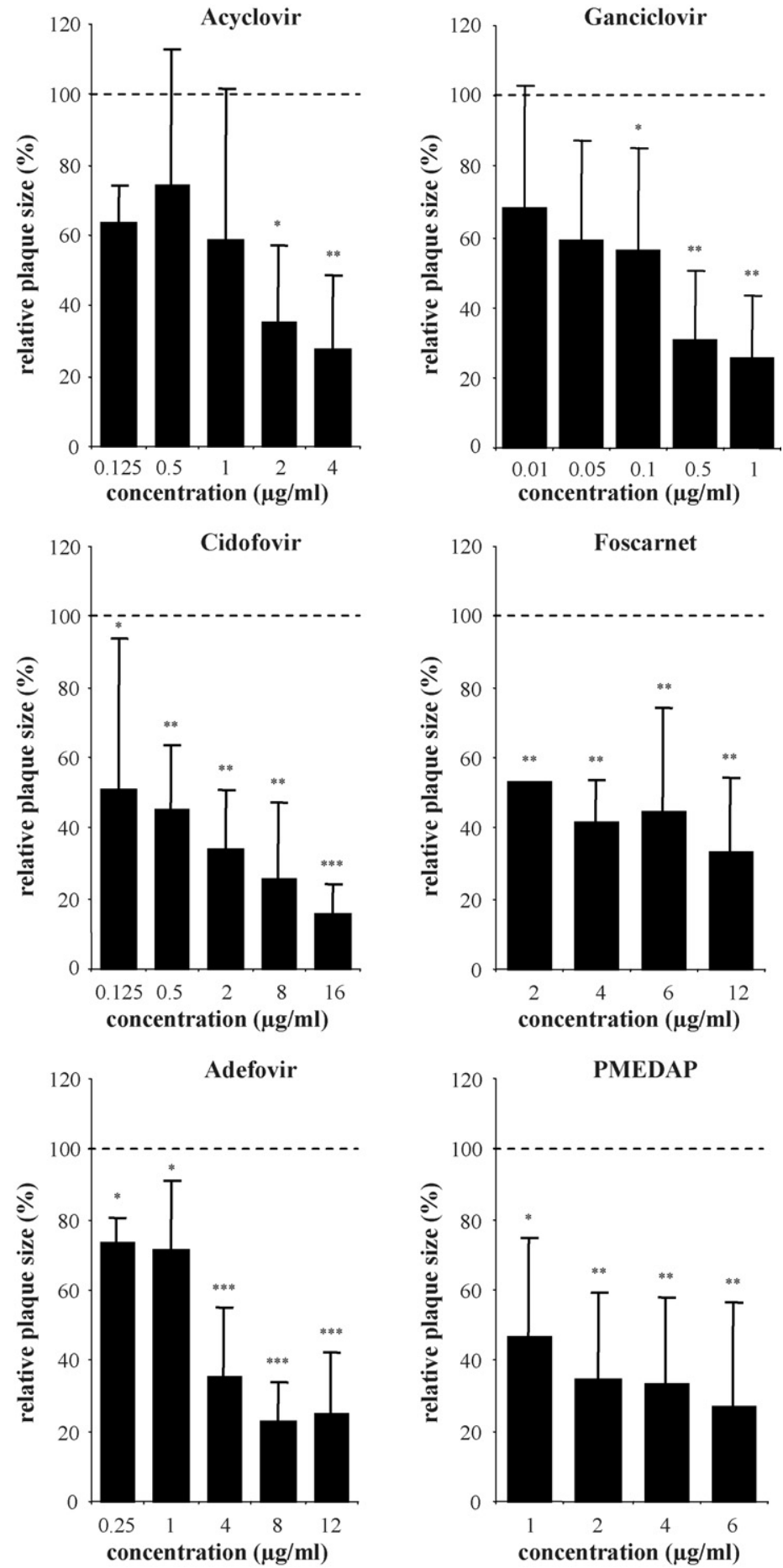

Fig. 1. The effect of antivirals on the size of virus-induced plaques. All products were able to reduce the plaque size significantly. The data represent the mean + S.D. of three independent experiments. Significant difference between test sample and untreated control (LSD, $\left.{ }^{*} P<0.05\right)$ $\left(0.01<{ }^{*} P<0.05 ; 0.001<{ }^{* *} P<0.01 ;{ }^{* * *} P<0.001\right)$. 
was comparable. Adefovir reduced plaque number at a concentration of $2.8-5.6 \mu \mathrm{g} / \mathrm{ml}$. For all four compounds, there was no difference in susceptibility between the various isolates. The efficacy of cidofovir (3.1-6.7 $\mu \mathrm{g} / \mathrm{ml}$ ) was comparable with the efficacy of adefovir, except for isolate 99P96. This isolate displayed a clearly lower $\mathrm{EC}_{50}$ for cidofovir $(1.1 \mu \mathrm{g} / \mathrm{ml})$. Foscarnet was the least effective compound $(6.6-11.1 \mu \mathrm{g} / \mathrm{ml})$ and susceptibility showed a marked variation among isolates. The isolates 99P136 and 03P37 were clearly less susceptible to foscarnet than the other isolates (15.8 and $16.2 \mu \mathrm{g} / \mathrm{ml}$ ).

\subsection{Effect of the antiviral compounds on plaque size}

As a complementary parameter of assessing the efficacy of the antiviral compounds, the mean plaque size (in pixels) of the antiviral treated relative to the size of plaques in untreated cultures was determined for isolate 97P70 (Fig. 1).

It is known that marked differences may occur in plaque size when EHV-1 is grown in vitro. Therefore, data obtained in the plaque size assay were subjected to an $F$-test to examine whether the variation in plaque size between samples was significantly different from the variation in plaque size within a sample (95\% confidence interval). Or, in other words, the $F$-test was used to answer the question whether variation in plaque size was merely an artefact or whether it was related to the use of antiviral drugs. It was found that all compounds exhibited a significant effect on plaque size. Using a post hoc LSD-test it was demonstrated that the reduction in plaque size was significant for all antiviral compounds when compared to the untreated control (95\% confidence interval).

Acyclovir reduced plaque size significantly at a concentration of $2 \mu \mathrm{g} / \mathrm{ml}$ or higher, ganciclovir at a concentration of $0.1 \mu \mathrm{g} / \mathrm{ml}$ or higher and PMEDAP at a concentration of $1 \mu \mathrm{g} / \mathrm{ml}$ or higher. Cidofovir, adefovir and foscarnet reduced plaque size significantly at respective concentrations of $0.125,0.25$ and $2 \mu \mathrm{g} / \mathrm{ml}$ or higher. The latter drugs are thus more effective (4-, 16- and 40-fold, respectively) in reducing plaque size than in reducing plaque number.

\subsection{Effect of the antiviral compounds on the viability of EEL-cells}

None of the compounds resulted in a significant decrease of viability of uninfected EEL cells at concentrations that were able to exert an antiviral effect. Acyclovir was toxic at a concentration of $320 \mu \mathrm{g} /$ $\mathrm{ml}$ or more, ganciclovir at a concentration of more than $500 \mu \mathrm{g} / \mathrm{ml}$, cidofovir at a concentration of $500 \mu \mathrm{g} / \mathrm{ml}$ or more, foscarnet at a concentration of $500 \mu \mathrm{g} / \mathrm{ml}$ or more, adefovir at a concentration of $80 \mu \mathrm{g} / \mathrm{ml}$ or more and PMEDAP at a concentration of $320 \mu \mathrm{g} / \mathrm{ml}$ or more (ANOVA, LSD, $P>0.03$ ).

\section{Discussion}

The present study was conducted to compare the efficacy of a selection of anti-herpetic drugs against six isolates of $\mathrm{EHV}-1$ in vitro. Based on the $\mathrm{EC}_{50}$-value for inhibition of plaque formation, ganciclovir emerged as the most potent compound against all six isolates. Acyclovir and PMEDAP were approximately 10-fold less effective and adefovir was approximately 20 -fold less effective than ganciclovir. For cidofovir and foscarnet, the efficacy was isolatedependent. Isolate 99P96 was more susceptible to cidofovir as it had a lower $\mathrm{EC}_{50}$-value than the other isolates. On the other hand, the isolates 03P37 and 99P136 were clearly less susceptible to foscarnet in comparison with the other isolates. There was no correlation between the susceptibility of an isolate to foscarnet and whether it was isolated from an outbreak of abortion or an outbreak of neurological disorders. Also, there was no correlation with the location or with the year of isolation. As foscarnet is the least potent compound against EHV-1 and as there is a great difference between various isolates in their susceptibility to this drug, foscarnet has no potential as a drug for the treatment of infected horses.

Based on the results of sequencing across the ORF30 region, we were not able to detect differences in susceptibility between non-neurological and neurological isolates. However, there are other ways to distinguish isolates which may have an influence on the susceptibility to antivirals. For example, isolates can also be distinguished in six strain groups by using ORF68 as strain group marker (Nugent et al., 2006). 
No conclusion could be drawn based on differences in ORF68, as all our isolates, except one, were assigned to one group. Also possible variations in ORF18 may be interesting to study as this gene encodes the processivity subunit of the DNA polymerase (Telford et al., 1998).

Antiviral compounds not only reduce the number of herpesvirus-induced plaques, they also contribute in the reduction of plaque size (Mikloska and Cunningham, 2001; Jenssen et al., 2004; van der Meulen et al., 2006b). We found that all compounds were able to significantly reduce EHV-1 induced plaque size. Thus, plaque size is a useful and complementary means of assessing antiviral efficacy. The lowest concentration that was able to significantly reduce plaque size approached the $\mathrm{EC}_{50}$ for acyclovir, ganciclovir and PMEDAP, while the other products were able to reduce plaque size at concentrations significantly lower than their $\mathrm{EC}_{50}$. The most remarkable effect was seen for cidofovir. Cidofovir was 40-fold more effective in reducing plaque size than in reducing the plaque number. The relevance of this finding in view of treatment of horses against EHV-1 induced disease remains to be determined. However, as already speculated by Mikloska and Cunningham (2001), a significant reduction of plaque size in vitro may be a potential parameter for the ability of an antiviral agent to restrict the size of virus-induced lesions in vivo.

Although the acyclic nucleoside analogues acyclovir and ganciclovir share a similar requirement for enzymatic phosphorylation, the relative high efficacy of ganciclovir, compared to acyclovir, is noteworthy. The better activity of ganciclovir may be related to a more efficient phosphorylation of ganciclovir to its $5^{\prime}$ monophosphate form by the EHV-1 thymidine kinase, a more efficient activation of the $5^{\prime}$-monophosphate form to the triphosphate metabolite by cellular kinases (Smee et al., 1985; De Clercq, 1993) or a more efficient inhibition of the viral polymerase by ganciclovir $5^{\prime}$-triphosphate than by acyclovir $5^{\prime}$ triphosphate (Smee et al., 1985; Mar et al., 1985). Also for the acyclic nucleoside analogues adefovir and PMEDAP, the difference in efficacy is remarkable. The study of Kramata and Downey (1999) suggests that differences in inhibition of cellular DNA synthesis may be explained by different intracellular ratios of the analogue diphosphates to their corresponding deoxynucleoside triphosphates and different affinities of DNA polymerases for the nucleotide analogue diphosphates.

From our results, we can conclude that ganciclovir displays the best overall activity against EHV-1 infection in vitro, without affecting cell viability. However, due to the high cost price, there is no direct clinical application possible. Therefore, acyclovir seems a more valuable candidate for antiviral therapy against EHV-1 infection in horses. As acyclovir is from patent since 1997 and generic alternatives are available, it seems attractive to use this drug for the treatment of horses during an outbreak. Previous studies (Wilkins et al., 2005) indicated that twice daily IV infusions of acyclovir $(10 \mathrm{mg} / \mathrm{kg})$ results in plasma concentrations above $\mathrm{EC}_{50}$-levels during the entire treatment interval. However, the $\mathrm{EC}_{50}$-value reported in their study was $0.3 \mu \mathrm{g} / \mathrm{ml}$, which is 10 fold lower than the one we found. Our $\mathrm{EC}_{50}$-value implies that the infusion should be given much more frequently, i.e. 8 times per day, to exceed concentrations greater than $1.7-3.0 \mu \mathrm{g} / \mathrm{ml}$ for the entire treatment interval. This limits the clinical application due to the high costs and practical administration during an outbreak. Oral administration of acyclovir may be an alternative. However, the bioavailability of orally administered acyclovir is a restriction. Bentz et al. (2006) reported a bioavailability of only $2.8 \%$ resulting in low plasma concentrations, inadequate to expect any clinically relevant antiviral efficacy. The oral prodrug of acyclovir, valacyclovir, may be more effective due to its higher bioavailability (Ormrod and Goa, 2000). Also the experimental compound PMEDAP can be a useful antiviral in the future. Although cidofovir is not highly efficient in reducing plaque number, it is able to significantly reduce plaque size at very low concentrations. As foscarnet is the least potent compound against EHV-1 and as there is a great difference between various isolates in their susceptibility to this drug, foscarnet has no potential as a drug for the treatment of infected horses.

\section{References}

Allen, G.P., Bryans, J.T., 1986. Molecular epizootiology, pathogenesis and prophylaxis of equine herpesvirus-1 infections. Prog. Vet. Microbiol. Immunol. 2, 78-144. 
Bentz, B.G., Maxwell, L.K., Erkert, R.S., Royer, C.M., Davis, M.S., MacAllister, C.G., Clarke, C.R., 2006. Pharmacokinetics of acyclovir after single intravenous and oral administration to adult horses. J. Vet. Intern. Med. 20, 589-594.

Boyd, M.R., Bacon, T.H., Sutton, D., Cole, M., 1987. Antiherpesvirus activity of 9-(4-hydroxy-3-hydroxymethylbut-1-yl)guanine (BRL 39123) in cell culture. Antimicrob. Agents Chemother. 31, 1238-1242.

Bryans, J.T., Allen, G.P., 1989. Herpesviral diseases of the horse. In: Wittman, G. (Ed.), Herpesviral Diseases of Cattle, Horses and Pigs. Kluwer, Boston, pp. 176-229.

Buchner, H.H.F., Mostl, K., 1998. Outbreak of an equine herpesvirus infection (EHV-1) in an university clinic. Wien. Tierarztl. Monatsschr. 85, 87-93.

De Clercq, E., 1993. Antivirals for the treatment of herpesvirus infections. J. Antimicrob. Chemother. 32 (Suppl. A), 121-132.

De Clercq, E., 2004. Antiviral drugs in current clinical use. J. Clin. Virol. 30, 115-133.

de la Fuente, R., Awan, R., Field, H.J., 1992. The acyclic nucleoside analogue penciclovir is a potent inhibitor of equine herpesvirus type $1($ EHV-1) in tissue culture and in a murine model. Antiviral Res. 18, 77-89.

Field, H.J., Awan, A.R., 1990. Effective chemotherapy of equine herpesvirus 1 by phosphonylmethoxylkyl derivatives of adenine demonstrated in a novel murine model for the disease. Antimicrob. Agents Chemother. 34, 709-717.

Foote, C.E., Love, D.N., Gilkerson, J.R., Wellington, J.E., Whalley, J.M., 2006. EHV-1 and EHV-4 infection in vaccinated mares and their foals. Vet. Immunol. Immunopathol. 111, 41-46.

Friday, P.A., Scarratt, W.K., Elvinger, F., Timoney, P.J., Bonda, A., 2000. Ataxia and paresis with equine herpesvirus type 1 infection in a herd of a riding school horses. J. Vet. Intern. Med. 14, 197-201.

Gibson, J.S., Slater, J.D., Field, H.J., 1992. The activity of (S)-1-[(3hydroxy-2-phosphonylmethoxy)propyl]cytosine (HPMPC) against equine herpesvirus-1 (EHV-1) in cell cultures, mice and horses. Antiviral Res. 19, 219-232.

Goehring, L.S., van Winden, S.C., van Maanen, C., Sloet van Oldruitenborgh-Oosterbaan, M.M., 2006. Equine herpesvirus type-1 associated myeloencephalopathy in the Netherlands: a four-year retrospective study (1999-2003). J. Vet. Intern. Med. 20, 601-607.

Goodman, L.B., Wagner, B., Flaminio, M.J.B.F., Sussman, K.H., Metzger, S.M., Holland, R., Osterreider, N., 2006. Comparison of the efficacy of inactivated combination and modified-live virus vaccines against challenge infection with neuropathogenic equine herpesvirus type 1 (EHV-1). Vaccine 24, 3636-3645.

Hansen, M.B., Nielsen, S.E., Berg, K., 1989. Re-examination and further development of a precise and rapid dye method for measuring cell growth/cell kill. J. Immunol. Methods 119, 203-210.

Jenssen, H., Andersen, J.H., Mantzilas, D., Gutteberg, T.J., 2004. A wide range of medium-sized, highly cationic, alpha-helical peptides show antiviral activity against herpes simplex virus. Antiviral Res. 64, 119-126.

Kramata, P., Downey, K.M., 1999. 9-(2-Phosphonylmethoxyethyl) derivatives of purine nucleotide analogs: A comparison of their metabolism and interaction with cellular DNA synthesis. Mol. Pharmacol. 56, 1262-1270.

Kohn, C.W., Lunn, P., Goehring, L.S., 2003. Equine herpesvirus-1 neurological disease: pathogenesis and recent outbreaks in Ohio, USA and the Netherlands. In: Proceedings of the American College of Veterinary Internal Medicine, Annual Forum, Charlotte, NC.

Kydd, H.H., Townsend, G.G.G., Hannant, D., 2006. The equine immune response to equine herpesvirus-1: the virus and its vaccines. Vet. Immunol. Immunopathol. 111, 15-30.

Mar, E.C., Chiou, J.F., Cheng, Y.C., Huang, E.S., 1985. Inhibition of cellular DNA polymerase alpha by the triphosphates of 9-(2hydroxyethoxymethyl)guanine and 9-(1,3-dihydroxy-2-propoxymethyl)guanine. J. Virol. 53, 776-780.

McMartan, C.G., Russell, M.M., Wood, J.L.N., Mumford, J.A., 1995. Clinical, serological and virological characteristics of an outbreak of paresis and neonatal foal disease due to equine herpesvirus-1 on a stud farm. Vet. Rec. 136, 7-12.

Mikloska, Z., Cunningham, A.L., 2001. Alpha and gamma interferons inhibit herpes simplex virus type 1 infection and spread in epidermal cells after axonal transmission. J. Virol. 75, 1182111826.

Nugent, J., Birch-Machin, I., Smith, K.C., Mumford, J.A., Swann, Z., Newton, J.R., Bowden, R.J., Allen, G.P., Davis-Poynter, N., 2006. Analysis of equid herpesvirus 1 strain variation reveals a point mutation of the DNA polymerase strongly associated with neuropathogenic versus nonneuropathogenic disease outbreaks. J. Virol. 80, 4047-4060.

Ormrod, D., Goa, K., 2000. Valaciclovir. A review of its use in the management of herpes zoster. Drugs 59, 1317-1340.

Ostlund, E.N., 1993. The equine herpesvirus. Vet. Clin. North Am. Equine Pract. 9, 283-294.

Patel, J.R., Heldens, J., 2005. Equine herpesviruses 1 (EHV-1) and 4 (EHV-4)—epidemiology, disease and immunoprophylaxis: a brief review. Vet. J. 170, 14-23.

Rollinson, E.A., White, G., 1983. Relative activities of acyclovir and BW759 against Aujeszky's disease and equine rhinopneumonitis viruses. Antimicrob. Agents Chemother. 24, 221-226.

Rollinson, E.A., 1987. Comparative efficacy of three 2 '-fluoropyrimidine nucleosides and 9-(1,3-dihydroxy-2-propoxymethyl)guanine (BW B759U) against pseudorabies and equine rhinopneumonitis virus infection in vitro and in laboratory animals. Antiviral Res. 7, 25-33.

Smee, D.F., Boehme, R., Chernow, M., Binko, B.P., Matthew, T.R., 1985. Intracellular metabolism and enzymatic phosphorylation of 9-(1,3-dihydroxy-2-propoxymethyl)guanine and acyclovir in herpes simplex virus-infected and uninfected cells. Biochem. Pharmacol. 34, 1049-1056.

Smith, K.O., Galloway, K.S., Hodges, S.L., Ogilvie, K.K., Radatus, B.K., Kalter, S.S., Heberling, R.L., 1983. Sensitivity of equine herpesvirus 1 and 3 in vitro to a new nucleoside analogue, 9-[[2hyrdoxy-1-(hydroxymethyl)ethoxy]methyl]guanine. Am. J. Vet. Res. 44, 1032-1035.

Stierstorfer, B., Eichhorn, W., Schmahl, W., Brandmuller, C., Kaaden, O.R., Neubauer, A., 2002. Equine herpesvirus type 1 (EHV1) myeloencephalopathy: a case report. J. Vet. Med. B Inf. Dis. Vet. Public Health 49, 37-41. 
Telford, E.A.R., Watson, M.S., Perry, J., Cullinane, A.A., Davison, A.J., 1998. The DNA sequence of equine herpesvirus-4. J. Gen. Virol. 79, 1197-1203.

van der Meulen, K.M., Nauwynck, H.J., Pensaert, M.B., 2000. Equine herpesvirus type 1 abortus, neonatale sterfte en zenuwstoornissen gediagnosticeerd in België in 1999. Flem. Vet. J. 69, $38-41$.

van der Meulen, K.M., Vercauteren, G., Nauwynck, H.J., Pensaert, M.B., 2003a. A local epidemic of equine herpesvirus 1-induced neurological disorders in Belgium. Flem. Vet. J. 72, 366-372.

van der Meulen, K.M., Nauwynck, H.J., Pensaert, M.B., 2003b. Absence of viral antigens on the surface of equine herpesvirus-1infected peripheral blood mononuclear cells: a strategy to avoid complement-mediated lysis. J. Gen. Vir. 84, 93-97. van der Meulen, K.M., Favoreel, H.W., Pensaert, M.B., Nauwynck, H.J., 2006a. Immune escape of equine herpesvirus 1 and other herpesviruses of veterinary importance. Vet. Immunol. Immunopathol. 111, 3-13.

van der Meulen, K.M., Garré, B., Croubels, S., Nauwynck, H.J., 2006b. In vitro comparison of antiviral drugs against feline herpesvirus 1. BMC Vet. Res. 2:13.

van Maanen, C., Sloet van Oldruiterborgh-Oosterbaan, M.M., Damen, E.A., Derksen, A.G., 2001. Neurological disease associated with EHV-1 infection in a riding school: clinical and virological characteristics. Equine Vet. J. 33, 191-196.

Wilkins, P.A., Papich, M., Sweeney, R.W., 2005. Pharmacokinetics of acyclovir in adult horses. J. Vet. Em. Crit. Care 15, 174-178. 